\title{
FUNGAL BIOFILMS ON METALLIC SURFACES
}

\author{
M.MOTA and L. MELO \\ Dep. Eng. Biologica \\ Universidade do Minho \\ Largo do Paço 4719 Braga Codex \\ PORTUGAL
}

\section{Introduction}

There are not many publications devoted to the study of the attachment of fungi to surfaces, the available articles being in general limited in scope as well as in perspective.

Fungi have not drawn much attention as far as adhesion is concerned. Yet, in the vast majority of interactions between fungi and the environment, prior attachment is needed.

This is the case of the biodeterioration of wood, as well as of other well known examples such as the moulding of stored foodstuffs, decay of paint and paint films, leather, books, paintings, adhesives and even glass (the etching of glass lenses in the tropics is of fungi's responsibility ) (Onions et al, 1986).

The adhesion of filamentous fungi to plastics and plasticizers was extensively studied by Pankhurst et al. (1972), Olson et al. (1977) and Pantke (1977) under the point of view of biodeteroration. The same perspective was adopted in the work of Mogilnitskii et al (1987), who investigated the biodeterioration of PVC. A study of the adhesion to perspex by marine fungi was also performed by Hyde et al (1989).

Growing attention is being recently paid to the detrimental effects of mycotoxins liberated by fungi into foodstuffs - namely ochratoxins and aflatoxins - since the latter have been incriminated as potent carcinogens and there are proofs of the toxicity of ochratoxins for mammals( Linsell, 1977; Ames, 1989).

The ochratoxins are of interest in food processing for at least three reasons: (1) they are toxic to several animal species, and probably to man also, (2) some are highly resistant to heat and (3) many fungi are capable of producing ochratoxins at storing temperatures, i.e., below $10^{\circ} \mathrm{C}$ ( Frazier and Westhoff, 1988 ).

Therefore, the prevention of the attachment of conidia to food processing surfaces is important, since spores are one of the major propagation ways of filamentous fungi. Only two references, both published by the same research team, were found in the literature ( Kaznacheev et al, 1986, 1989). These two papers were devoted to the attachment onto polymers, namely cellophane and epoxy resins. As cellophane and epoxy resins are 
widely used materiais for food packaging, this may be considered a valuable work in the field of food processing.

Nevertheless, adhesion to important surfaces in food processing, such as metals and metal alloys, have unfortunately been little considered so far. A survey in the literature revealed one publication concerning the corrosion of metals by biofilms of fungi ( Rosales et al, 1990 ) dealing with the corrosion produced by Cladosporium resinae. Cladosporium strains are not major food contaminants (Jay, 1978), let alone the strain used in this work, in which food contamination was not a matter of concern.

The other work studying adhesion to metals was that of Andreyuk et al (1982). In this case, the biofouling was studied on steel surfaces dipped in seawater, corresponding to conditions which in no way can be compared to those found in food spoilage and contamination (except for the special case of curing).

In summary, we can see that the adhesion of food spoilage fungi such as Aspergillus, Penicillium, Candida, etc., to food processing surfaces has been poorly studied so far. To give another example of the lack of research in this field it is just enough to point out that there was not a single communication on biofilm formation by fungi in the important filamentous fungi symposium that was recently held in Yugoslavia (Physiological Aspects of Product Formation by Filamentous Fungi - Programme and Abstracts - 4-7 Nov 1990, Gozd Martuljek).

The study of fungi adhesion activity is also important in the field of wastewater treatment. As a matter of fact, fungi play an important role in the treatment of liquid wastes, being either beneficial, by removing xenobiotics (Glaser,1990) or detrimental, when they give rise to filamentous bulking (Atlas and Bartha, 1987). Furthermore, main treatment processes either aerobic - viz. trickling filters and rotating biological contactors $(\mathrm{RBC})$ - or anaerobic - anaerobic filters and expanded beds, for example - are attachedgrowth waste treatment processes (Metcalf and Eddy, 1991).

Little published work can be useful to this field. Indeed, the above mentioned publications concern either plastic supports which are not used in attached-growth processes, or the wrong fungi. Once more, this is an open field to active investigation.

In the present work, an experimental set-up is described and used for the assessment of the adhesion ability of filamentous fungi to different metallic surfaces. The experimental conditions used in this preliminary work are equivalent to those normally found both in food processing and in waste treatment.

\section{Materials and Methods}

\section{ORGANISMS}

The following fungi were used:

Aspergillus niger van Tieghen was purchased from the FCL collection (Lisbon, Portugal): Geotrichum candidum Link ex Persoon and Candida lipolytica( Harrison) Diddens \& Lodder were kindly furnished by Dr. Amaral-Collaço from LNETI ( Lisbon, Portugal). 


\section{CULTURE MEDIUM}

The medium was composed of $0.5 \%$ peptone and $0.3 \%$ yeast extract dissolved in tap water.

\section{EXPERIMENTAL SET UP}

The experimental set-up is depicted in figure 1.The metal plates were turned to the central axis of the flask. The rotation speed of the magnetic bar was adjusted to the desired value with the help of a stroboscopic meter.

\section{METALS AND ALLOYS}

The metals and alloys assayed were stainless steel, aluminium, copper, zinc and brass. The assayed metallic plates were polished, thoroughly rinsed, dried and weighed before the attachment runs. Plastified wires were used to suspend the plates and dip them at the same level in the culture medium.

\section{PREPARATION, INCUBATION AND MEASUREMENTS}

The $500 \mathrm{~mL}$ erlenmeyer flasks containing $200 \mathrm{~mL}$ of culture medium and the metallic plates were sterilized in an autociave at $121^{\circ} \mathrm{C}$ for 15 minutes. The inocula were obtained by transferring 2 loops of a slant culture to a $100 \mathrm{~mL}$ conical flask containing $25 \mathrm{~mL}$ of culture medium with the above described composition. After an incubation in an orbital shaker for 48 hours at $30^{\circ} \mathrm{C}, 10 \mathrm{~mL}$ were pipetted into the $500 \mathrm{~mL}$ flask containing the metal plates. The cultures were allowed to grow for 1 week at $30^{\circ} \mathrm{C}$ as represented in fig. 1. The stirring speed was adjusted to $150 \mathrm{rpm}$. After 1 week growth, the metal plates were carefully removed from the culture, dried at $105^{\circ} \mathrm{C}$ till constant weight and weighed again in a $0.1 \mathrm{mg}$ precision balance. The culture medium was filtered through previously weighed 0.45 micron membrane filters, which, after a drying period at $105^{\circ} \mathrm{C}$, were weighed again to measure the biomass dry weight suspended in the culture.

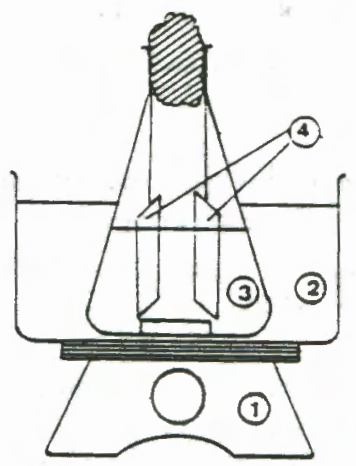

Figure 1 - Experimental set-up for the assessment of biofilm formation: 1- magnetic stirrer, 2 - water bath, 3 - erlenmeyer flask, 4 - metal plates. 


\section{Results and Discussion}

Each dry weight allowed to assess 1) the mass of filamentous fungi attached per unit mass of the metal plate and 2) the fraction of the whole biomass which became attached to the plates.

The results obtained for each strain and metal are represented in Tables 1 and 2.

TABLE 1. Results obtained (in grams), for the total grown biomass, the suspended biomass and the adhered biomass, corresponding to each strain and each kind of metallic plate.

\begin{tabular}{llccc}
\hline Metal/alloy & Biomass & G.candidum & C.lipolytica & A.niger \\
\hline \multirow{2}{*}{ STEEL } & Plates & 0.0247 & 0.0123 & 1.6872 \\
& Suspended & 0.3130 & 0.0610 & 3.7650 \\
& Total & 0.3372 & 0.0733 & 5.4522 \\
& & & & \\
ALUM. & Plates & 0.0281 & 0.0386 & 0.4796 \\
& Suspended & 0.2104 & 0.3973 & 3.7081 \\
& Total & 0.2385 & 0.4359 & 4.1877 \\
& & & & \\
BRASS & Plates & 0.0149 & 0.0250 & 0.0309 \\
& Suspended & 0.1841 & 0.0385 & 0.7854 \\
& Total & 0.1990 & 0.0635 & 0.8163 \\
& & & & \\
ZINC & Plates & 0.7012 & 0.2595 & 0.5178 \\
& Suspended & 0.3581 & 0.1757 & 0.2575 \\
& Total & 1.0593 & 0.4352 & 0.7753 \\
& & & & \\
COPPER & Plates & 0.0256 & - & 0.0025 \\
& Suspended & 0.0812 & - & 0.0529 \\
& Total & 0.1068 & 0.0018 & 0.0554
\end{tabular}

TABLE 2 . Proportion (in \%) of biomass that adhered to the metallic plates for each strain

\begin{tabular}{lccccc}
\hline & Steel & Al & Brass & Zinc & Copper \\
\hline G.candidum & 7.3 & 11.8 & 7.5 & 66.2 & 24.0 \\
C.lipolytica & 8.2 & 8.9 & 39.4 & 59.6 & - \\
A.niger & 30.9 & 11.5 & 3.8 & 66.8 & 4.5 \\
\hline
\end{tabular}


From these results, it may be seen that zinc promotes a significant growth of all the strains. Furthermore, in the case of zinc, the growth is mainly located on the plates for all the strains. Curiously, zinc has been shown to inhibit the adhesion of bacteria ( Duddridge et al, 1981; Vieira et al.,1992) The influence of the other metals is largely strain-dependent which may be seen when the second best metal for adhesion is identified. The second best metal after zinc is copper for G.candidum, brass for C.lipolytica and steel for A.niger. The comparison of the results obtained for zinc, copper and brass leads to the conclusion that copper is the main responsible for the lower growth in the brass plates, because the growth in the presence of zinc alone is several times greater, except for A.niger.

Liberation of metallic ions to the culture medium was also evaluated. Analysis by atomic absorption spectrophotometry showed that i) concentrations of copper and zinc in the spent culture medium were 10 times higher than in the fresh medium, ii) the concentration of iron decreased during the experiment, meaning that there was a consumption of that metal, and iii) aluminium concentration did not vary. The significant increase in the concentrations of copper and zinc in solution may justify different physiological behaviours of the strains as far as total growth is concerned.

\section{Conclusions}

As the metal plates were turned to the rotation axis, the adhering cells were undergoing shear forces all along the growing and attachment process. As a consequence of the conical geometry of the flask and of the proximity of the walls, there are different liquid speeds at different levels on the metallic plates. Thus, the linear liquid speed cannot be calculated exactly. Nevertheless, although it is not a procedure as sophisticated and rigourous as those described by Fletcher (1990), it allowed us to assess the adhesion of various fungi to different surfaces. Furthermore, it proved 1) that if we want to build a food processing facility, the materials to be used must be chosen according to fungi more susceptible to contaminate the plant and 2) that each organism has a different adhesion ability, varying according to the metal in use, which means that adhesion studies should be performed in each particular case. This procedure is now in course of application to other fungi and materials.

\section{AKNOWLEDGEMENTS}

The authors want to aknowledge the contribution in laboratory work the students A.P.Castro and N.Coelho have given to this research.

\section{References}

Ames, BN (1989) 'Chemicals, cancers, causalities and cautions', Chemtech, Oct., 590598.

Andreyuk, EI, Kopteva, ZhP, Yanova, SB, et al. (1982) 'Growth of microorganisms on the surfaces of steels 09G2 and 10KhSND in seawater and different seasons of the year', Mikrobiol.Zh., Vol.44, 3, pp.16-19 (in russian). 
Atlas,RM and Bartha,R (1987) Microbial Ecology: Fundamentals and Applications, 2nd Ed., Benjamin Cummings Pub Co.,MenloPark, Cal.

Duddridge,JE, Kent,CA and Law,JF (1981) 'Bacterial adhesion to metallic surfaces' in Progress in Prevention of Fouling, Nottingham University, 137, April.

Fletcher,M (1990) 'Methods for Studying Adhesion and Attachment to Surfaces', in R.Grigorova and JR Norris (eds.), 'Methods in Microbiology', vol.22, Academic Press, London, pp. 251-283.

Frazier,Wc and Westhoff,DC (1988) Food Microbiology, 4th Ed., McGraw-Hill Book Co., New York.

Glaser,JA (1990) 'Hazardous waste degradation by wood degrading fungi', in D.Kamely, A.Chakrabarty and G.S.Omenn (eds.),'Biotechnology and Biodegradation', Gulf Pub. Co., Houston, pp.267-284.

Hyde,KD, Moss,ST and Gareth Jones,EB (1989) 'Attachment studies in marine fungi', Biofouling, Vol.I, pp. 287-298.

Jay.J (1978) Modern Food Microbiology, D Van Nostrand Co., New York.

Kaznacheev,IV, Gumargalieva,KZ and Moiseev,Yu.V(1986) ' Adhesion of Aspergillus nigerconidia to different polymeric surfaces', Dokl.Akad.Nauk.USSR, Vol.291, 5, pp.1241-1244 (in russian).

Kaznacheev,IV, Gumargalieva,KZ, Moiseev, Yu.V and Mironova,SN (1989) 'Change in the level of adhesion of conidia in relation to the composition of the cell wall and the age of the culture', Mikrobiol.Zh., Vol.51., 6, pp. 63-67 (in russian).

Linsell, CA (1977)'Aflatoxins', in JJ Lenihan and WW Fletcher (eds.) Environment and Man, Vol.6. The Chemical Environment, Blackie, Glasgow and London, pp. 121-136.

Metcalf and Eddy (1991) Wastewater Engineering: treatment, disposal, reuse, McGrawHill Book Co., 3rd Ed.,New York.

Mogilnitskii,GM, Sagatelyan,RT, Kutischeva,TN, Zhukova,SV, Kerimov,SI and Parfenova,TB (1987) 'Deterioration of the protective properties of PVC coating by microorganisms', Zasch, Met., Vol.23, 1, pp. 173-175 (in russian).

Onions, AHS, Allsopp and Eggins, HOW (1986) Smith's Introduction to Industrial Mycology, 7th Ed., Edward Arnold, London.

Osmon,JL and KlausMeier,RE (1977)'Techniques for assessing biodeterioration of plastics and plasticizers', in AH Walters (ed.), Biodeterioration Investigation Techniques, Applied Science, London, pp. 77-94.

Pankhurst,ES, Davies,MJ and Blake,HM (1972) 'The ability of polymers or materials containing materials to provide a source of carbon for selected microorganisms', in AH Walters and EH Hueck van der Plas (eds.), Biodeterioration of Materials, Applied Science, London, pp. 76-90.

Pantke,M (1977) "Test methods for evaluation of susceptibility of platicized PVC and its components to microbial attack', in AH Walters (ed.), Biodeterioration Investigation Techniques, Applied Science, London, pp. 51-76.

Rosales,BM and Esteso,MA (1990) ' Microbiologically induced corrosion of metals by biofilms of fungi', Rev.Iberoam.Corros.Prot., Vol.21, 5, pp. 171-175 (in spanish).

Vieira,MJ, Oliveira,R, Melo,L , Pinheiro,MM and Martins, V (1992) 'Adhesion of biofilms formed by Pseudomonas fluorescens', Colloids and Surfaces (accepted). 